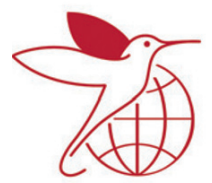

\title{
Clinical safety and effectiveness of biphasic insulin aspart 30 in type 2 diabetes patients switched from biphasic human insulin 30: Results from the Indonesian cohort of the $\mathrm{A}_{1}$ chieve study
}

\author{
Pradana Soewondo ${ }^{a, *}$, Dharma Lindarto ${ }^{b}$, Sony Wibisono ${ }^{c}$, Olly Renaldi ${ }^{d}$, \\ Tjokorda Gde Dalem-Pemayun ${ }^{e}$ \\ ${ }^{a}$ University of Indonesia, Cipto Mangunkusomo Hospital, Jakarta, Indonesia \\ ${ }^{b}$ Division of Endocrine Metabolic, Department of Internal Medicine, H Adam Malik Hospital, Medan, Indonesia \\ ${ }^{c}$ Diabetes and Nutrition Centre, Dr. Soetomo Hospital, School of Medicine Airlangga University, Surabaya, Indonesia \\ ${ }^{\mathrm{d}}$ Mitra Bekasi Barat Hospital, Bekasi, Indonesia \\ ${ }^{e}$ Diponegoro University, Kariadi Hospital, Semarang, Indonesia
}

\section{ARTICLE INFO}

Keywords:

Switch

Biphasic human insulin 30

Biphasic insulin aspart 30

Indonesia

\begin{abstract}
A B S T RAC T
Aim: To evaluate the safety and effectiveness of biphasic insulin aspart 30 (BIAsp 30) in Indonesian type 2 diabetes patients switched from biphasic human insulin 30 (BHI 30) as a sub-analysis of the $A_{1}$ chieve study.

Methods: Clinical safety and effectiveness over 24 weeks was evaluated in Indonesian patients who switched from BHI 30 to BIAsp 30 at the discretion of their physician.

Results: A total of 244 patients with mean age \pm SD $55.6 \pm 9.5$ years, BMI $24.6 \pm 3.8 \mathrm{~kg} / \mathrm{m}^{2}$, and mean diabetes duration 7.8 \pm 5.7 years were included. The mean pre-study BHI 30 dose was $0.56 \pm 0.25 \mathrm{IU} / \mathrm{kg}$ and the baseline BIAsp 30 dose was $0.60 \pm 0.26 \mathrm{U} / \mathrm{kg}$ titrated up to $0.65 \pm 0.25 \mathrm{U} / \mathrm{kg}$ by Week 24. No serious adverse drug reactions were reported throughout the study. Overall hypoglycaemia decreased from 2.18 to 0.06 events/patient-year with a significant decrease in the proportion of patients affected $(\mathrm{p}<0.0001)$. No nocturnal or major hypoglycaemia was reported at Week 24 . $\mathrm{HbA}_{1 \mathrm{c}}$ improved from $8.8 \pm 1.2 \%$ at baseline to $7.3 \pm 0.8 \%$ at Week 24 . A total of 45 patients achieved $\mathrm{HbA}_{1 \mathrm{c}}<7.0 \%$ as compared to 5 patients with $\mathrm{HbA}_{1 \mathrm{c}}<7.0 \%$ at baseline. FPG and PPPG improved significantly after 24 weeks $(p<0.001)$. Quality of life was positively impacted (change in visual analogue scores, $3.0 \pm 11.6$ points, $\mathrm{p}<0.001$ ).

Conclusion: Switching from BHI 30 to BIAsp 30 in this Indonesian cohort was well-tolerated and improved glycaemic control with a decreased risk of hypoglycaemia.
\end{abstract}

(c) 2013 Elsevier Ireland Ltd. All rights reserved.

\section{Introduction}

The prevalence of diabetes in Indonesia is projected to increase from 7.3 million in 2011 to 11.8 million in 2030 among people in the age group of 20-79 years [1].
Indonesia also ranks among the top 10 countries for diabetes prevalence worldwide and has the second highest number of diabetes cases in the Western Pacific region [1,2]. A crosssectional study in Indonesia indicated that age, smoking, obesity and hypertension were the primary determinants

\footnotetext{
* Corresponding author at: Sp-PD-KEMO, Division of Endorinology, Department of Internal Medicine, Faculty of Medicine, University of Indonesia, Cipto Mangunkusomo Hospital, Jakarta, Indonesia. Tel.: +62 21390 7703; fax: +62 213928659.

E-mail address: soewondops@yahoo.com (P. Soewondo).

0168-8227/\$ - see front matter @ 2013 Elsevier Ireland Ltd. All rights reserved.
} 
of impaired glucose tolerance leading to a high risk of diabetes [3]. There is an immense need to contain this growing epidemic with the help of early intensification of adequate therapy.

According to the United Kingdom Prospective Diabetes Study, insulin therapy is ultimately required in all patients with type 2 diabetes (T2D) due to its chronic progressive nature that causes a continual decline in $\beta$-cell function [4]. However, it is observed that compliance to insulin therapy is very poor owing to barriers such as fear of hypoglycaemia, weight gain and the negative impact on quality of life (QoL) [5]. Furthermore, glycaemic control, especially postprandial glucose, with human insulin preparations such as biphasic human insulin 30 (BHI 30) is often sub-optimal and efficacy is largely dependent on the time of injection. The slow onset of action with BHI 30 therapy necessitates injecting the drug at least 30 minutes prior to meals. Hence, in case of erratic meal timings, BHI 30 is rendered ineffective to control postprandial glucose levels [6,7].

The insulin analogue, biphasic insulin aspart 30 (BIAsp 30), has a more physiological pharmacokinetic and pharmacodynamic profile as compared to BHI 30 that enables more convenient dosing [8]. Furthermore, short- and longterm studies have proven that the frequency of major hypoglycaemia in patients using BIAsp 30 twice-daily (bid) is lower than those on the same BHI 30 regimen [9-11]. Boehm et al. demonstrated that although the $\mathrm{HbA}_{1 \mathrm{c}}$ lowering effect of BIAsp 30 was comparable to $\mathrm{BHI} 30$, the former resulted in more favorable postprandial glucose control [10]. In addition to data from RCTs, observational studies - IMPROVE and PRESENT - have also concluded that switching from BHI 30 to BIAsp 30 improves glycaemic control without increasing the risk of hypoglycaemia [12-16].

$A_{1}$ chieve [14] was a multinational, prospective, noninterventional study to determine the safety and efficacy of insulin analogues, including BIAsp 30 in routine clinical care in 28 countries across Asia, Africa, Latin America and Europe. The overall results from all countries are available online under www.A1chieve.com. The current clinical practice guidelines in Indonesia are a simplified set of recommendations on screening and diagnosis of pre-diabetes and diabetes that are derived from diabetes organizations in the US [17]. This is largely due to the absence of local study data that is specific and applicable only to Indonesia. In this sub-analysis of the $\mathrm{A}_{1}$ chieve study, we aim to shed light on the existing status of T2D management in Indonesia and evaluate the clinical effects of BIAsp 30 in patients that received prior BHI 30 therapy.

\section{Methods}

\subsection{Study design}

The $A_{1}$ chieve study [14] was a 24-week, non-interventional study to evaluate the safety and effectiveness of BIAsp 30 (Novomix $30^{\circledR}$, Novo Nordisk, Denmark), insulin detemir (Levemir ${ }^{\circledR}$, Novo Nordisk, Denmark) and insulin aspart (NovoRapid ${ }^{\circledR}$, Novo Nordisk, Denmark), alone or in combination with oral glucose-lowering drugs (OGLDs). This sub-analysis focuses on T2D patients from Indonesia that switched therapy from BHI 30 to BIAsp 30. These patients were recruited between October 2009 and August 2010 at 65 centers in Indonesia. The study was approved by the local ethics committee of Indonesia. Based on a mutual agreement between the patients and their consulting physicians, T2D therapy was switched from BHI 30 to BIAsp 30. The dosing, frequency of administration, and subsequent changes were at the discretion of the physician. The study drug was commercially available and used in accordance with local regulations. The study procedures were not pre-defined and all assessments were made by physicians during routine clinical visits. Data for analysis from the physicians' clinical notes and patients' recall and self-monitoring diary/blood glucose meter was collected at baseline, Week 12 and Week 24 and transferred to a standard case report form (CRF).

\subsection{Patients}

All patients recruited from Indonesia who switched therapy from BHI 30 to BIAsp 30 were included in this sub-analysis. Patients who had received any of the study insulin analogues 4 weeks prior to the study were excluded. Pregnant women or those intending to become pregnant or were breastfeeding were also excluded. Signed informed consent was obtained from all patients and they could withdraw from the study at any time. After withdrawal, the data collected were used for analysis until the time that consent was withdrawn.

\subsection{Outcome measures and assessments}

The primary objective of this study was to evaluate the clinical safety of BIAsp 30 as determined by the incidence of serious adverse drug reactions (SADRs), including major hypoglycaemic events from baseline to final visit. Secondary safety assessments included changes in number of hypoglycaemic events in the last 4 weeks prior to baseline and final visit, changes in nocturnal hypoglycaemia during this period and the number of adverse drug reactions.

Glycaemic control was evaluated using changes in $\mathrm{HbA}_{1 \mathrm{c}}$ levels, fasting plasma glucose (FPG) and post-breakfast postprandial glucose (PPPG) from baseline to Week 24. The change in lipid profile, systolic blood pressure (SBP), and body weight was also reported. All laboratory parameters were measured in local laboratories and were subject to local standardization and quality control procedures. Healthrelated QoL was assessed using the EQ-5D questionnaire that rates patient pain/discomfort, anxiety/depression, mobility, usual activity and self-care. Subsequently, the current QoL was measured using a standard vertical $20 \mathrm{~cm}$ visual analogue scale (VAS, 0-100 [worst imaginable health to best imaginable health]).

\subsection{Statistical methods}

Continuous and discrete variables were summarized using descriptive statistics and frequency tables (n [\%]), respectively. The paired t-test was used to analyse the changes 
in $\mathrm{HbA}_{1 \mathrm{c}}$, FPG and PPPG, SBP, blood lipids, body weight and QoL from baseline to Week 24. P-values were not reported when the number of patients evaluated was less than 100 . The McNemar test was used to analyse the change in the proportion of patients reporting at least one hypoglycaemic event from baseline to Week 24. All data were analysed by Novo Nordisk using SAS (Version 9.1.3).

\section{Results}

\subsection{Patient characteristics}

A total of 244 patients from the Indonesian cohort of the $A_{1}$ chieve study switched from BHI 30 to BIAsp 30 . Demographic and baseline characteristics for the entire cohort are reported in Table 1 . The average duration of

\begin{tabular}{|c|c|}
\hline Parameter & Entire cohort $(n=244)$ \\
\hline Gender (male/female), \% & $50.4 / 49.6$ \\
\hline Age, years & $55.6(9.5)$ \\
\hline Body weight, kg & $64.0(11.8)$ \\
\hline BMI, $\mathrm{kg} / \mathrm{m}^{2}$ & $24.6(3.8)$ \\
\hline Diabetes duration, years & $7.8(5.7)$ \\
\hline Duration on prior insulin therapy, years & $1.9(1.5)$ \\
\hline $\mathrm{HbA}_{1 \mathrm{c}}, \%$ & $8.8(1.2)$ \\
\hline $\mathrm{HbA}_{1 \mathrm{c}}, \mathrm{mmol} / \mathrm{mol}$ & $73(13)$ \\
\hline \multicolumn{2}{|l|}{ Prior OGLDs, n (\%) } \\
\hline Metformin & $152(82.2)$ \\
\hline Sulfonylureas & $59(31.9)$ \\
\hline Thiazolidinediones & $8(4.3)$ \\
\hline 1 OGLD & $139(75.1)$ \\
\hline 2 OGLDs & $27(14.6)$ \\
\hline$>2$ OGLDs & $19(10.3)$ \\
\hline
\end{tabular}

$\mathrm{BMI}$, body mass index; $\mathrm{HbA}_{1 \mathrm{c}}$, glycated haemoglobin $\mathrm{A}_{1 \mathrm{c}}$; OGLD(s), oral glucose lowering drug(s).

Data are mean (SD) unless specified otherwise.

diabetes was $7.8 \pm 5.7$ years and the mean duration on prior insulin therapy was $1.9 \pm 1.5$ years. At baseline, patients reported a mean $\mathrm{HbA}_{1 \mathrm{c}}$ level of $8.8 \pm 1.2 \%$ and 5 patients, $6.9 \%$ of the cohort, had $\mathrm{HbA}_{1 \mathrm{c}}$ values $<7.0 \%(<53 \mathrm{mmol} / \mathrm{mol})$. Physicians decided to switch therapy in $93.4 \%$ patients in order to improve glucose control. Other prominent reasons for switching therapy were to try new insulin (75.0\% patients) and to reduce plasma glucose variability (58.2\% patients).

\subsection{Insulin dose}

The mean pre-study BHI 30 dose was $0.56 \pm 0.25 \mathrm{IU} / \mathrm{kg}$ in the entire cohort (Table 2). At baseline, patients initiated an average BIAsp 30 dose of $0.60 \pm 0.26 \mathrm{U} / \mathrm{kg}$ that was titrated up to $0.65 \pm 0.25 \mathrm{U} / \mathrm{kg}$ by Week 24 . The majority of patients received BIAsp 30 twice-daily (bid) at baseline $(95.9 \%$ patients) and Week 24 (90.8\% patients).

\begin{tabular}{lll} 
Table 2 - Insulin dose and frequency & \\
\hline Parameter & $\mathrm{n}$ & Entire cohort \\
\hline Insulin dose by day & Pre-study, & 244 \\
& IU/day & $35.1(15.9)$ \\
& Baseline, U/day & $38.1(16.6)$ \\
& Week 24, U/day & $41.3(15.3)$ \\
Insulin dose by body weight & n & 242 \\
& Pre-study, IU/kg & $0.56(0.25)$ \\
& Baseline, U/kg & $0.60(0.26)$ \\
& Week 24, U/kg & $0.65(0.25)$ \\
& Pre-study (n) & 244 \\
Dose frequency, n (\%) & Once daily & $2(0.8)$ \\
& Twice daily & $232(95.1)$ \\
& Thrice daily & $10(4.1)$ \\
IU/kg. & Baseline (n) & 244 \\
Once daily & $2(0.8)$ \\
& Twice daily & $234(95.9)$ \\
& Thrice daily & $8(3.3)$ \\
& Week 24 (n) & 228 \\
& Once daily & $5(2.2)$ \\
& Twice daily & $207(90.8)$ \\
& & $13(5.7) / 3(1.3)$ \\
\hline
\end{tabular}

\subsection{SADRs and SAEs}

From baseline to Week 24, no SADRs or SAEs were reported in patients that switched therapy to BIAsp 30 .

\subsection{Hypoglycaemia}

The proportion of patients reporting overall hypoglycaemia decreased significantly from baseline (8.2\%) to Week 24 $(0.4 \%, p<0.0001$, Table 3$)$. The corresponding decrease in the incidence of overall hypoglycaemia was from 2.18 events/ patient-year at baseline to 0.06 events/patient-year at Week 24. No nocturnal or major hypoglycaemic events were reported at Week 24 (Table 3).

\section{Table 3 - Baseline and 24-week data for hypoglycaemia}

\begin{tabular}{lll} 
Hypoglycaemia & \multicolumn{2}{l}{ Events per patient-year / } \\
& Percent with at least one event \\
\hline Overall & Baseline & $2.18 / 8.2$ \\
& Week 24 & $0.06 / 0.4$ \\
& P & $<0.0001$ \\
Minor & Baseline & $2.18 / 8.2$ \\
& Week 24 & $0.06 / 0.4$ \\
Nocturnal & P & $<0.0001$ \\
& Baseline & $0.64 / 4.5$ \\
& Week 24 & $0.0 / 0.0$ \\
Major & P & 0.0009 \\
& Baseline & $0.0 / 0.0$ \\
& Week 24 & $0.0 / 0.0$ \\
& P & - \\
\hline
\end{tabular}

$\mathrm{p}$-values are from McNemar test on paired proportions of patients experiencing hypoglycaemia. 

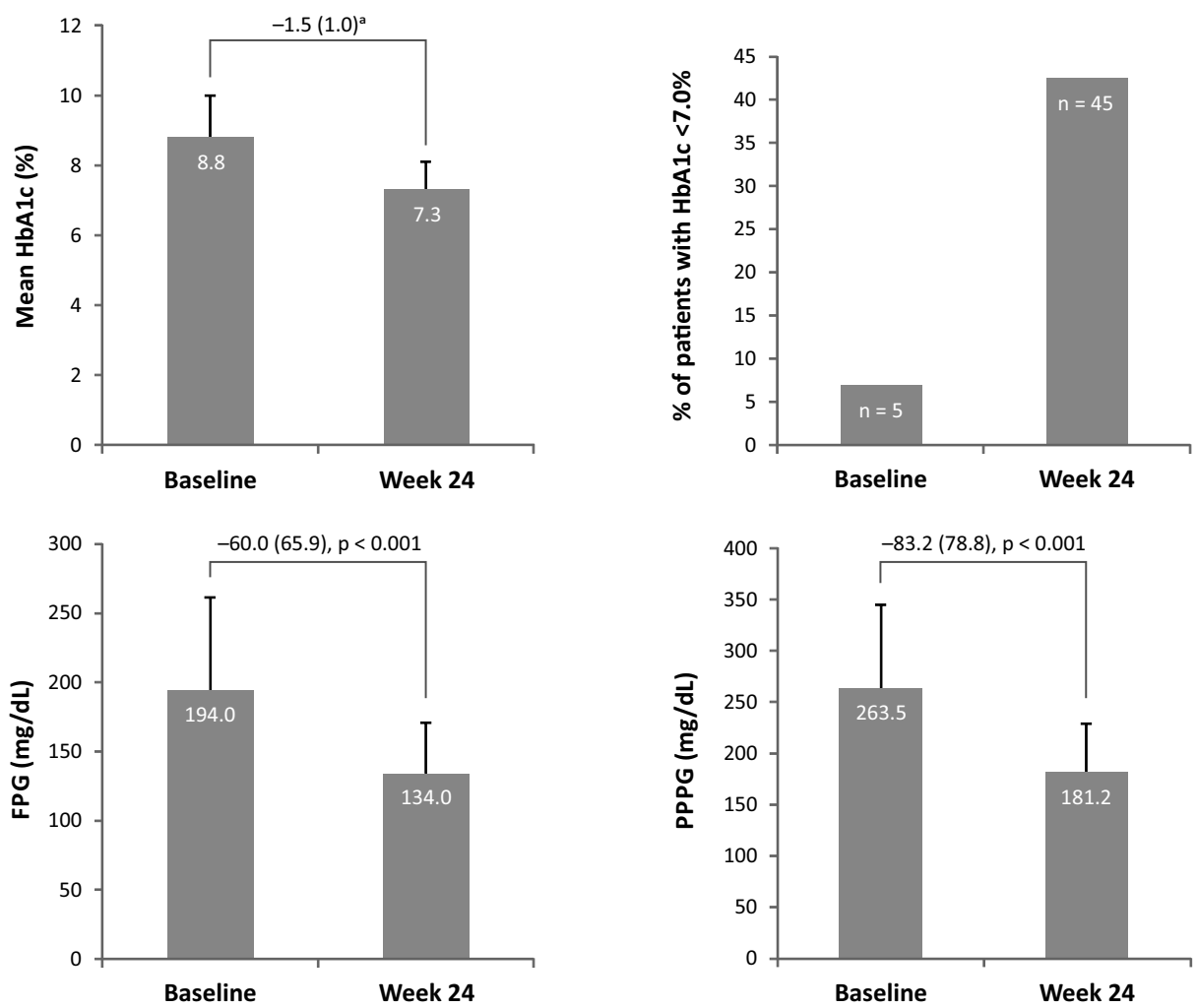

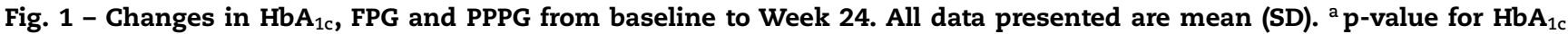
not reported since $\mathbf{n}<100$.

\subsection{Glucose control}

The mean $\mathrm{HbA}_{1 \mathrm{c}}$ level in the entire cohort decreased from $8.8 \pm 1.2 \%(73 \pm 13 \mathrm{mmol} / \mathrm{mol})$ at baseline to $7.3 \pm 0.8 \%$ $(56 \pm 9 \mathrm{mmol} / \mathrm{mol})$ at Week 24 . The proportion of patients achieving $\mathrm{HbA}_{1 \mathrm{c}}$ target levels $<7.0 \% \quad(<53 \mathrm{mmol} / \mathrm{mol})$ increased from $6.9 \%(n=5)$ at baseline to $42.5 \%(n=45)$ at Week 24. Significant decreases in FPG and PPPG were also observed after 24 weeks of BIAsp 30 therapy $(p<0.001$, Figure 1).

\subsection{Body weight, lipids and SBP}

The mean body weight increased by $0.8 \pm 3.9 \mathrm{~kg}$ from baseline to Week $24(p=0.003)$. At Week 24, total cholesterol decreased by $0.3 \pm 1.6 \mathrm{mmol} / \mathrm{L}$, low-density lipoprotein cholesterol decreased by $0.3 \pm 1.2 \mathrm{mmol} / \mathrm{L}$ and triglycerides decreased by $0.1 \pm 0.7 \mathrm{mmol} / \mathrm{L}$ while high-density lipoprotein cholesterol increased by $0.2 \pm 0.5 \mathrm{mmol} / \mathrm{L}$. A significant decrease in SBP of $3.4 \pm 15.0 \mathrm{mmHg}$ was observed in the entire cohort following 24 weeks of BIAsp 30 treatment $(p=0.001)$ (Table 4).

\subsection{Quality of life}

The QoL improved significantly from $78.9 \pm 13.0$ points at baseline to $82.0 \pm 8.7$ points at Week 24 (mean change, $3.0 \pm 11.6$ points, $\mathrm{p}<0.001)$.
Table 4 - Lipid profile, SBP, body weight and

hypoglycaemia in the entire cohort

\begin{tabular}{|c|c|c|}
\hline \multicolumn{2}{|l|}{ Parameter } & \multirow{2}{*}{$\begin{array}{l}\text { Mean (SD) } \\
5.4(1.3)\end{array}$} \\
\hline Total cholesterol, $\mathrm{mmol} / \mathrm{L}(\mathrm{n}=44)$ & Baseline & \\
\hline & Week 24 & $5.1(1.1)$ \\
\hline & Change & $-0.3(1.6)$ \\
\hline & $\mathrm{p}$ & $-{ }^{a}$ \\
\hline \multirow[t]{4}{*}{ HDL cholesterol, $\mathrm{mmol} / \mathrm{L}(\mathrm{n}=33)$} & Baseline & $1.3(0.5)$ \\
\hline & Week 24 & $1.5(0.3)$ \\
\hline & Change & $0.2(0.5)$ \\
\hline & $\mathrm{p}$ & $--^{a}$ \\
\hline \multirow[t]{4}{*}{ LDL cholesterol, mmol/L $(\mathrm{n}=37)$} & Baseline & $3.5(1.1)$ \\
\hline & Week 24 & $3.2(0.8)$ \\
\hline & Change & $-0.3(1.2)$ \\
\hline & $\mathrm{p}$ & $-{ }^{a}$ \\
\hline \multirow[t]{4}{*}{ Triglycerides, $\mathrm{mmol} / \mathrm{L}(\mathrm{n}=40)$} & Baseline & $1.7(0.7)$ \\
\hline & Week 24 & $1.6(0.7)$ \\
\hline & Change & $-0.1(0.7)$ \\
\hline & $\mathrm{p}$ & $--^{a}$ \\
\hline \multirow[t]{4}{*}{$\mathrm{SBP}, \mathrm{mmHg}(\mathrm{n}=212)$} & Baseline & $131.4(14.3)$ \\
\hline & Week 24 & $128.0(12.4)$ \\
\hline & Change & $-3.4(15.0)$ \\
\hline & $\mathrm{p}$ & 0.001 \\
\hline \multirow[t]{4}{*}{ Body weight, $\mathrm{kg}(\mathrm{n}=219)$} & Baseline & $63.7(11.4)$ \\
\hline & Week 24 & $64.5(10.3)$ \\
\hline & Change & $0.8(3.9)$ \\
\hline & $\mathrm{p}$ & 0.003 \\
\hline
\end{tabular}




\section{Discussion}

This sub-analysis demonstrated the safety and effectiveness of BIAsp 30 therapy in Indonesian T2D patients previously treated with BHI 30. At baseline, this cohort presented with poor glycaemic control. This observation is reflected in the $\mathrm{A}_{1}$ chieve data [14] from other countries as well. Additionally, the delay in insulin intiation was evident in this cohort as the average diabetes duration was $7.8 \pm 5.7$ years but patients had been on insulin therapy for $1.9 \pm 1.5$ years only.

Evidence-based guidelines from the American Diabetes Association recommend a glycaemic target of $\mathrm{HbA}_{1 \mathrm{c}}$ levels $<7.0 \%(<53 \mathrm{mmol} / \mathrm{mol})$ that can be achieved by maintaining FPG at $130 \mathrm{mg} / \mathrm{dL}$ and PPPG at $180 \mathrm{mg} / \mathrm{dL}$ [18]. At baseline, patients failed to achieve any of these targets with BHI 30 (HbA1c, 8.8 $\pm 1.2 \%, 73 \pm 13 \mathrm{mmol} / \mathrm{mol}$; FPG, $194.0 \pm 67.4 \mathrm{mg} / \mathrm{dL}$; PPPG, $263.5 \pm 81.3 \mathrm{mg} / \mathrm{dL}$ ). However, after 24 weeks of BIAsp 30 therapy, significant improvements were observed in $\mathrm{HbA}_{1 \mathrm{c}}$ $(7.3 \pm 0.8 \%, \quad 56 \pm 9 \mathrm{mmol} / \mathrm{mol}), \quad$ FPG $(134.0 \pm 36.9 \mathrm{mg} / \mathrm{dL})$ and PPPG $(181.2 \pm 47.6 \mathrm{mg} / \mathrm{dL})$. Furthermore, the proportion of patients reporting $\mathrm{HbA}_{1 \mathrm{c}}$ target levels $<7.0 \%(<53 \mathrm{mmol} / \mathrm{mol})$ increased from $6.9 \%(n=5)$ at baseline to $42.5 \%(n=45)$ at Week 24. The increase in body weight was modest and SBP improved significantly. Notably, these improvements were observed with a very small increase in dose from $0.60 \pm 0.26 \mathrm{U} / \mathrm{kg}$ at baseline to $0.65 \pm 0.25 \mathrm{U} / \mathrm{kg}$ at Week 24 .

While achieving and maintaining glycaemic control is the primary aim of T2D management, it is also important to reduce the risk of hypoglycaemia associated with intensive therapy. BIAsp 30 therapy could effectively decrease the occurrence of hypoglycaemia in this Indonesian cohort. There was no major hypoglycaemia reported in the entire cohort at baseline or final visit. A significant decrease in the proportion of patients reporting overall, minor and nocturnal hypoglycaemia was observed. Previously, a crossover study also demonstrated that individuals on BHI 30 reported higher rates of nocturnal hypoglycaemia when compared to those on BIAsp 30 therapy [19]. The efficiency of glycaemic control and reduction in the risk of hypoglycaemia in patients treated with BIAsp 30 was also observed in the overall $\mathrm{A}_{1}$ chieve cohort receiving pre-study BHI 30 [20]. Previously, similar data had also been reported in the PRESENT and IMPROVE studies from other regions worldwide [15,16].

Anti-diabetic therapy often has a major impact on the health and well-being of patients, primarily owing to the risk of hypoglycaemia. In this Indonesian cohort it was observed that the QoL as measured using the EQ-5D questionnaire significantly improved in patients after 24 weeks of BIAsp 30 treatment. These results could be a contributing factor to improving patient compliance to therapy.

Due to the observational study design, the results are subject to obvious limitations such as lack of a control arm, retrospective data collection methods and nonstandardization of reported data. Also, recall bias may have been introduced in the reporting of hypoglycaemia. Nevertheless, this study provides an opportunity to witness the safety and effectiveness on BIAsp 30 therapy in heterogeneous local clinical settings. Observational studies such as these are also more reliable in terms of reporting safety in a wider population which may otherwise be masked in the restricted cohorts of randomized controlled trials [21]. In conclusion, the switch from BHI 30 to BIAsp 30 in Indonesian T2D patients was well-tolerated and improved glycaemic control while decreasing the risk of hypoglycaemia.

\section{Acknowledgements}

The authors would like to thank the entire study group, their staff, clinical trial personnel and investigators involved in the $A_{1}$ chieve study. Special thanks to all the patients and investigators for their participation in this study. The authors would like to thank Chunduo Shen of Novo Nordisk for providing statistical analysis. The authors would also like to thank Ruchita Kapoor from Cognizant Technology Solutions for writing assistance, funded by Novo Nordisk.

\section{Conflict of interest statement}

Dr. Pradana Soewondo has authored an article sponsored by Novo Nordisk and sanofi aventis, and has served as a consultant (Advisory Board) for Novo Nordisk, sanofi aventis, and Novartis. Dr. Pradana Soewondo has also received research grants from World Diabetes Foundation and grants for lectures from Novo Nordisk, sanofi aventis, Novartis and MSD. Dr. Tjokorda Gde Dalem-Pemayun has served as a consultant (Advisory board) for MSD, AstraZeneca and sanofi aventis and has received honorarium for lectures from Novo Nordisk, sanofi aventis, Merck, MSD, AstraZeneca, Eli Lilly and Kalbe Farma. No other author has any conflict of interest to report. This study was sponsored by Novo Nordisk A/S, Denmark. The sponsor took part in the development of the protocol, the process of data collection and analysis, funding of medical writing services, and in reviewing the manuscript, but not in participant selection, choice of therapies (study or otherwise), provision of therapies including insulin or continuing clinical management of the participants.

\section{REFERENCES}

[1] Whiting DR, Guariguata L, Weil C, Shaw J. IDF diabetes atlas: global estimates of the prevalence of diabetes for 2011 and 2030. Diabetes Res Clin Pract 2011;94(3):311-21.

[2] International Diabetes Federation. IDF Diabetes Atlas. 5th edn. Brussels, Belgium; 2011, updated 14 November 2012.

[3] Mihardja L, Delima, Manz HS, Ghani L, Soegondo S. Prevalence and determinants of diabetes mellitus and impaired glucose tolerance in Indonesia (a part of basic health research/Riskesdas). Acta Med Indones 2009;41(4):169-74.

[4] Wright A, Burden ACF, Paisey RB, Cill CA, Holman RR, and the UK Prospective Diabetes Study Group. Sulphonylurea inadequacy: efficacy of addition of insulin over 6 years in patients with type 2 diabetes in the UK. Prospective Diabetes Study (UKPDS 57). Diabetes Care 2002;25:330-6. 
[5] Niswender K. Early and aggressive initiation of insulin therapy for type 2 diabetes: What is the evidence? Clin Diab 2009;27:60-8.

[6] Heller S. Reducing hypoglycaemia with insulin analogues. Int J Obes Relat Metab Disord 2002;26(Suppl 3):S31-6.

[7] Evans M, Schumm-7raeger PM, Vora J, King AB. A review of modern insulin analogue pharmacokinetic and pharmacodynamic profiles in type 2 diabetes: improvements and limitations. Diabetes Obes Metab 2011;13(8):677-84.

[8] Jacobsen LV, Sogaard B, Riis A. Pharmacokinetics and pharmacodynamics of a premixed formulation of soluble and protamine-retarded insulin aspart. Eur J Clin Pharmacol 2000;56:399-403.

[9] Boehm BO, Vaz JA, Brøndsted L, Home PD. Long-term efficacy and safety of biphasic insulin aspart in patients with type 2 diabetes. Eur J Intern Med 2004;15:496-502.

[10] Boehm BO, Home PD, Behrend C, Kamp NM, Lindholm A. Premixed insulin aspart 30 vs. premixed human insulin 30/70 twice daily: a randomized trial in type 1 and type 2 diabetic patients. Diabet Med 2002;19:393-9.

[11] Davidson JA, Liebl A, Christiansen JS, Fulcher G, Ligthelm RJ, Brown P, et al. Risk for nocturnal hypoglycemia with biphasic insulin aspart 30 compared with biphasic human insulin 30 in adults with type 2 diabetes mellitus: a meta-analysis. Clin Ther 2009;31:1641-51.

[12] Velojic-Golubovic M, Mikic D, Pesic M, Dimic D, Radenkovic S, Antic S. Biphasic insulin aspart 30: better glycemic control than with premixed human insulin 30 in obese patients with type 2 diabetes. J Endocrinol Invest 2009;32:23-7.

[13] Schmoelzer I, de Campo A, Pressl H, Stelzl H, Dittrich P, Oettl K, et al. Biphasic insulin aspart compared to biphasic human insulin reduces postprandial hyperlipidemia in patients with type 2 diabetes. Exp Clin Endocrinol Diabetes 2005;113:176-81.

[14] Home P, Naggar NE, Khamseh M, Gonzalez-Galvez G, Shen C, Chakkarwar P, et al. An observational noninterventional study of patients with diabetes beginning or changed to insulin analogue therapy in non-Western countries: The $\mathrm{A}_{1}$ chieve study. Diabetes Res Clin Pract 2011;94:352-63.

[15] Shah S, Benroubi M, Borzi V, Gumprecht J, Kawamori R, Shaban J, et al.; on behalf of the IMPROVE Study Group Expert Panel. Safety and effectiveness of biphasic insulin aspart 30/70 (NovoMix 30) when switching from human premix insulin in patients with type 2 diabetes: subgroup analysis from the 6-month IMPROVE observational study. Int J Clin Pract 2009;63:574-82.

[16] Shestakova M, Sharma SK, Almustafa M, Min KW, Ayad N, Azar ST, et al. Transferring type 2 diabetes patients with uncontrolled glycaemia from biphasic human insulin to biphasic insulin aspart 30: experiences from the PRESENT study. Curr Med Res Opin 2007;23(12):3209-14.

[17] Paz-Pacheco E. Diabetes Clinical Practice Guidelines (CPGs) for the ASEAN region: Country initiatives for collectively enhanced diabetes care in the region. JAFES 2011;26(1): 36-7.

[18] Inzucchi SE, Bergenstal RM, Buse JB, Diamant M, Ferrannini E, Nauck M, et al. Management of hyperglycaemia in type 2 diabetes: a patient-centered approach. Position statement of the American Diabetes Association (ADA) and the European Association for the Study of Diabetes (EASD). Diabetologia 2012;55(6):1577-96.

[19] McNally PG, Dean JD, Morris AD, Wilkinson PD, Compion G, Heller SR. Using continuous glucose monitoring to measure the frequency of low glucose values when using biphasic insulin aspart 30 compared with biphasic human insulin 30: a double-blind crossover study in individuals with type 2 diabetes. Diabetes Care 2007;30:1044-8.

[20] El Naggar NK, Soewondo P, Khamseh ME, Chen J, Haddad J. Switching from biphasic human insulin 30 to biphasic insulin aspart 30 in type 2 diabetes is associated with improved glycaemic control and a positive safety profile: Results from the $\mathrm{A}_{1}$ chieve study. Diabetes Res Clin Pract 2012;98(3):408-13.

[21] Vandenbroucke JP. What is the best evidence for determining harms of medical treatment? CMAJ 2006;174(5):645-6. 